\title{
Os Centros de Atenção Psicossocial como espaços promotores de vida: relatos da desinstitucionalização em Alagoas
}

\section{The Psychosocial Care Centers as spaces promoters of life: reports of deinstitutionalization in Alagoas}

\author{
Mara Cristina Ribeiro
}

http://dx.doi.org/10.11606/issn.2238-6149.v24i3p174-82

Ribeiro MC. Os Centros de Atenção Psicossocial como espaços promotores de vida: relatos da desinstitucionalização em Alagoas. Rev Ter Ocup Univ São Paulo. 2013 set.-dez.;24(3):174-82.

RESUMO: Este trabalho é recorte de uma investigação que buscou traçar a trajetória de construção do novo modelo de cuidado em saúde mental no estado de Alagoas. Tendo como referencial teórico a desinstitucionalização, o artigo trata da passagem do cuidado realizado nos hospitais psiquiátricos para o cuidado realizado no território, por meio dos CAPS, na perspectiva de seus usuários, familiares e trabalhadores. Utilizou-se a metodologia qualitativa para abordar o tema, na modalidade História Oral Temática, guiada por entrevistas para a produção dos dados e análise temática para a discussão dos seus resultados. A pesquisa aponta, entre outros resultados, que a criação desses serviços trouxe para os sujeitos, que antes só tinham a internação como experiência de cuidado, uma nova perspectiva. As relações constituídas a partir dessa nova forma de cuidado não mais se limitam às relações do tratamento biomédico ou das tão limitadas ações psiquiátricas, mas são relações constituídas no compromisso social do coletivo para que se possa garantir um novo lugar social para as pessoas em sofrimento psíquico.

PALAVRAS-CHAVE: Saúde mental; Desinstitucionalização; Reforma dos serviços de saúde; Serviços de saúde mental.
Ribeiro MC. The Psychosocial Care Centers as spaces promoters of life: reports of deinstitutionalization in Alagoas. Rev Ter Ocup Univ São Paulo. 2013 set.-dez.;24(3):174-82.

ABSTRACT: This study is part of a research that aimed to trace the path of the new model of care in mental health in the state of Alagoas. Within the theoretical perspective of the deinstitutionalization, the paper discusses the transition of the care taken by psychiatric hospitals to the care provided in the territory, through CAPS, in view of its users, families and workers. It was elected the qualitative research strategy, in the Thematic Oral History method, guided interviews for the data producing and the findings were submitted to the Thematic Analysis technique. The survey found, among other results, that the creation of these services brought to the subjects, who had previously only as hospitalization care experience, a new perspective. The relationships built through this new form of care no longer limited to the relations of the biomedical treatment or psychiatric such limited actions, but relations are incorporated in the collective social engagement so that we can ensure a new social place for people in psychic suffering .

KEYWORDS: Mental health; Deinstitutionalization; Health care reform; Mental health services.

\footnotetext{
* Este artigo faz parte da Tese de Doutorado em Ciências intitulada "A saúde mental em Alagoas: trajetória da construção de um novo cuidado", defendida na USP em 2012.

Terapeuta Ocupacional, Professora Adjunta do Curso de Terapia Ocupacional da Universidade Estadual de Ciências da Saúde de Alagoas. Endereço para correspondência: Rua Machado de Assis, 12, Guaxuma. CEP 57.038-731, Maceió, AL, Brasil. E-mail: marauncisal@ yahoo.com.br
} 


\section{INTRODUÇÃO}

$\mathbf{N}$ a modernidade, ao perceber a loucura como doença, a ciência cria para o seu entendimento dois personagens: o sujeito da doença (o paciente) e o sujeito detentor do seu conhecimento (o médico psiquiatra); no estabelecimento da relação desses dois personagens, inspira-se uma nova relação com ela (a observação médica), e uma nova atitude para transformá-la (a terapêutica). Na busca dessa transformação, cria novos espaços de transição (a instituição psiquiátrica).

Afastado do mundo social, o sujeito da doença, durante mais de dois séculos, só é reconhecido em sua manifestação doente e sua existência, enquanto paciente, só é permitida dentro dos muros institucionais para ele edificados.

Estas instituições, em conjunto com outras que foram criadas com funções semelhantes - afastar da sociedade mais ampla, por um considerável período de tempo, o que ela não reconhece como seu - foram denominadas por Goffman ${ }^{1}$ de instituições totais.

Durante mais de dois séculos o ritmo da vida nessas instituições foi marcado por regras forçadas e mortificações dos sujeitos nelas inseridos ${ }^{2}$. A organização desses espaços fechados e o isolamento imposto resultaram em um processo denominado de institucionalização, percebido por Basaglia ${ }^{2}$ como um tipo de doença resultante do vazio emocional vivido pelo doente ao transpor os muros do internamento.

$\mathrm{Na}$ transição paradigmática da modernidade para a pós-modernidade o conhecimento científico produzido é relativizado e as suas verdades que, por tanto tempo nos guiaram, começam a ser questionadas. A pós-modernidade abre caminhos para novas teorias do sujeito no cerne da ciência. Afastada da concepção simplificadora da ciência clássica, a questão da ciência e da ação pode ser modificada por uma visão que deu sentido às noções de ator, autonomia, liberdade e sujeito.

Nessa perspectiva, os processos de reestruturação das sociedades europeias e norte-americanas no período após as duas grandes guerras mundiais vão promover uma série de questionamentos ligados à existência dessas instituições e determinarão a necessidade de mudanças.

Inglaterra, França, Estados Unidos, Itália entre outros países vão, ao longo das décadas seguintes a este período, intensificar as críticas à assistência psiquiátrica vigente e criar novos modelos de prática assistencial. Algumas no interior do próprio hospital psiquiátrico, outras em instituições ligadas a ele e, ainda outras, marcadas pela ruptura com ele.

A noção de desinstitucionalização foi estabelecida no interior desse processo de reforma e, segundo Rotelli et al. ${ }^{3}$ as transformações que se seguiram nos sistemas de saúde mental tinham o intuito de renovar a capacidade terapêutica da Psiquiatria, desvencilhando-a de suas clássicas funções de controle social, coação e segregação.

O embasamento teórico para a presente investigação considera o termo desinstitucionalização proposto na visão de Franco Basaglia, que entende projeto de transformação institucional como descontrução/invenção no campo do conhecimento, das tecnociências, das ideologias e da função dos técnicos e intelectuais ${ }^{4}$.

Nesta acepção, a verdadeira desinstitucionalização, nas palavras de Rotelli ${ }^{5}$ (p.91) é o "processo prático-crítico que reorienta instituições e serviços, energias e saberes, estratégias e intervenções em direção a este tão diferente objeto".

Para a desconstrução dos aparatos asilares o foco deve também ser dirigido para a construção de serviços e espaços que deem sustentação à vida fora dos muros manicomiais, criando espaços de trocas reais - trocas afetivas, trocas materiais, trocas simbólicas; opondo-se à privação imposta pela vivência manicomial que se configura, como revelado por Rotelli ${ }^{5}$, em local de troca zero.

A desinstitucionalização, portanto, defende a criação de um novo lugar de pertencimento social para as pessoas com sofrimento psíquico e, no âmbito do Brasil, tem sido relacionada de forma concomitante ao movimento da Reforma Psiquiátrica brasileira.

Este nasce entre o final dos anos 1970 e início dos anos 1980, impulsionado por um contexto de luta social contra a ditadura militar e a favor da melhoria da condição de vida. Surgem denúncias de maus-tratos em vários hospícios do país, além das condições precárias de trabalho nesses locais e denúncias de fraudes no sistema de financiamento dos leitos conveniados.

Nesse período as ideias de Basaglia chegam ao Brasil e passam a se constituir, em conjunto com outras concepções e obras como as de Foucault, Goffman, Castel, entre outras, influências importantes na constituição de "um pensamento crítico sobre a natureza e a função social das práticas médicas e psiquiátrico-psicológicas"6 (p.90).

O cuidado em saúde mental no Brasil, nos últimos 35 anos aproximadamente, tem apresentado transformações das mais diversas ordens. Desde o marco inicial dessas mudanças, com a criação do Movimento dos Trabalhadores de Saúde Mental em 1978, passando à aprovação da Lei 10.216 em 2001, até suas subsequentes alterações, percebese uma gama significativa de ações que têm como objetivo alterar a realidade desse cuidado, impulsionando o processo de desinstitucionalização por meio da criação e ampliação da rede de cuidados em saúde mental.

Atualmente, essa rede pode ser composta por setores da atenção básica, como as unidades básicas de saúde, as equipes de saúde da família, os Núcleos de Apoio à Saúde da Família (NASF) e os Consultórios na Rua; por 
setores ligados aos serviços especializados como os Centros de Atenção Psicossocial (CAPS), os ambulatórios de saúde mental e hospitais-dia, os Centros de Convivência e Cultura, entre outros; além de serviços de urgência e emergência psiquiátrica, leitos ou unidades em hospital geral e as residências terapêuticas.

Com a publicação da Portaria GM 1.935, de 2004, que estabelece incentivo financeiro para a implantação dos CAPS e a sua substituta GM 245 de 2005 que aprimora este incentivo e o amplia, pôde-se verificar um aumento significativo dos CAPS, principalmente nos municípios de menor porte, contribuindo para a interiorização da assistência extra-hospitalar. Se em 2004 existiam apenas 605 CAPS, fecha-se o ano de 2011 com 1742 CAPS implantados e distribuídos por todo o país (Brasil, 2012)7. Em Alagoas, no ano de 2004 apenas 7 CAPS estavam em funcionamento, no início de 2012 verificamos a existência de 47 CAPS implantados.

Os CAPS são serviços integrados à rede SUS criados no bojo da Reforma Psiquiátrica Brasileira e, portanto, de caráter substitutivo aos hospitais psiquiátricos. Abertos e comunitários, têm como objetivo atender pessoas com transtorno mental severo e persistente, oferecendo cuidados na perspectiva clínica e da reabilitação psicossocial, sob a lógica da territorialidade. O cuidado oferecido nesses espaços deve estar alinhado de forma integral e intensiva, ofertando respostas às diversas dificuldades apresentadas por seus usuários no desenrolar de suas vidas cotidianas.

Para tanto, o CAPS trabalha com equipes multidisciplinares em ações interdisciplinares, oferecendo atendimentos individuais e grupais, oficinas terapêuticas, oficinas de geração de renda, atividades lúdicas, desportivas, tratamento medicamentoso, atendimento familiar, entre outras estratégias para garantir a construção de um lugar social aos seus usuários e estimular seu protagonismo frente à vida.

A pesquisa apresentada trata da passagem do cuidado realizado nos hospitais psiquiátricos em Alagoas para o cuidado realizado no território, por meio dos CAPS. Traz a percepção daqueles que vivenciaram as transformações discorrendo sobre o entendimento do cuidado em saúde mental nos diferentes contextos e o que representa o cuidado nos CAPS em suas vidas.

\section{PROCEDIMENTOS METODOLÓGICOS}

Como cenário para a pesquisa optou-se pelos Centros de Atenção Psicossocial, por representarem praticamente os únicos serviços alternativos ao hospital psiquiátrico no estado de Alagoas. Desta forma, foram escolhidos dois CAPS da capital, Maceió (o mais antigo e o mais recente) e dois CAPS do interior do Estado (também o mais antigo e o mais recente).

Foram sujeitos da pesquisa os usuários, familiares e trabalhadores dos serviços CAPS buscados e entrevistados no próprio serviço. No total foram entrevistados cinco usuários dos serviços, quatro familiares e oito trabalhadores. Com relação à formação dos trabalhadores, participaram do estudo: um Assistente Social, um Enfermeiro, dois Psiquiatras, dois Psicólogos e dois Terapeutas Ocupacionais.

Para a produção dos dados optou-se pelo método da História Oral Temática. Assim, com o propósito de fazer emergir a vivência, a experiência e a percepção dos participantes, utilizou-se um roteiro com perguntas norteadoras que versaram sobre a percepção de mudanças no cuidado recebido ao longo de sua história (para os usuários e familiares), sobre a percepção do cuidado recebido no CAPS (para usuários e familiares) e sobre a percepção das transformações ocorridas no estado de Alagoas, com relação ao cuidado em saúde mental (para os trabalhadores).

Todos os critérios éticos foram assumidos e a pesquisa foi previamente aprovada pelo Comitê de Ética da Universidade Estadual de Ciências da Saúde de Alagoas sob o código de protocolo de $\mathrm{n}^{\mathrm{o}}$ 1374/2010.

O referencial teórico - metodológico que subsidiou a análise dos temas selecionados foi a técnica de Análise de Conteúdo de Bardin ${ }^{8}$, especificamente a Análise Temática, que pode ser traduzida em uma técnica que procura nas expressões verbais ou textuais os temas gerais recorrentes e ou relevantes, busca descobrir os núcleos de sentido que compõem uma comunicação (via entrevista, registros e observação) e, cuja presença ou frequência signifiquem algo para o objetivo da pesquisa, fornecendo assim subsídios técnicos científicos para a interpretação dos resultados, além de ser considerada bastante apropriada para as pesquisas qualitativas em saúde?

\section{APRESENTAÇÃO E DISCUSS ÃO DOS RESULTADOS*}

Após as leituras de assimilação, utilizando critérios de relevância e de repetição e o aprofundamento da análise com o cruzamento das falas de todos os sujeitos que participaram da pesquisa e tendo o objetivo da pesquisa como pano de fundo, pôde-se identificar três temas comuns:

\footnotetext{
* Para melhor entendimento e organização da apresentação dos resultados e como forma de proteger a identificação dos entrevistados, serão utilizadas as siglas T nas falas dos trabalhadores técnicos dos CAPS, U nas falas dos usuários dos CAPS e F nas falas dos familiares de usuários dos CAPS; Na atualidade, existem 5 hospitais psiquiátricos em Alagoas, como estes foram citados nas falas, para proteger suas identidades, utilizaremos as siglas HP1, HP2, HP3, HP4 e HP5 quando nos referirmos a eles.)
} 
CAPS;

Tema 1: A polaridade Hospital Psiquiátrico X cuidado;

Tema 2: O CAPS como instância de ação do

Tema 3: O CAPS e seus usuários: da dor à liberdade.

\section{Tema 1: A polaridade Hospital Psiquiátrico X CAPS}

Durante anos, os hospitais psiquiátricos dominaram o campo da assistência às pessoas portadoras de transtornos mentais e, somente dentro de suas estruturas, o cuidado era exercido e reconhecido como tratamento.

$\mathrm{O}$ incremento das mudanças que a Reforma Psiquiátrica trouxe para o campo do cuidado gerou um grande movimento oposicionista, desvelando críticas ao velho modelo de cuidado e intensificando o debate sobre a polaridade entre a assistência prestada nos hospitais psiquiátricos e a assistência prestada nos serviços substitutivos, como os CAPS.

Desta forma, a criação desses serviços trouxe para os sujeitos, que antes só tinham a internação como experiência de cuidado, uma nova perspectiva.

Esta polaridade fica bastante evidente nas falas dos entrevistados ao fazerem, de forma espontânea, comparações entre o cuidado recebido nos dois campos assistenciais, o hospital psiquiátrico (HP) e o CAPS:

Não tem nem o que comparar porque no $\boldsymbol{H P 1}$, aquilo era o inferno, aqui $[\boldsymbol{C A P S}]$ é o céu. (U1)

Lá $[\boldsymbol{H P}]$ é um verdadeiro calabouço, é um verdadeiro ai, ei, ui, muita gente e é muito sofrimento... e aqui [CAPS] é mais tranquilo, mais tranquilidade... Eu não quero voltar mais pra o HP1. É melhor 10 mil $\boldsymbol{C A P S}$ do que entrar uma vez só no $\boldsymbol{H P 1}$. (U2)

Quando eu fui pra o $\boldsymbol{H P 3}$, pra mim foi um inferno... Não é muito bom pras pessoas, estar lá, porque eu passei um sofrimento danado... Sofri demais... E aqui [CAPS] é o melhor lugar que tem. [...] aqui tem saída $[\boldsymbol{C A P S}]$... Mas lá $[\boldsymbol{H P}]$ não, lá você só vê o Sol e o chão... Aqui não, aqui tem livre arbítrio. Fica de manhã até 5 horas, vai pra casa e na rua faz o que quiser... Aqui tem liberdade... (U5)

Essa visão também é compartilhada pelos familiares dos usuários, que em suas falas descrevem experiências e percepções:

[...] que aqui $[\boldsymbol{C A P S}]$ faz de conta que é em casa... é perto de casa... E lá no $\boldsymbol{H P 1}$, minha filha, ele só faltava morrer de fome, porque ele não comia a comida de lá, só comia quando eu levava de casa ou pagava na cantina pra ele comer. Aqui eu acho melhor. (F2)

Eu gosto do tratamento do $\boldsymbol{C A P S}$. Eu gosto do tratamento do CAPS porque o $\boldsymbol{C A P S}$ não lhe amarra, e no $\boldsymbol{H P} 4$ amarrava ele ... (F4)

Falas produzidas a partir da construção crítica das mudanças ocorridas e do que o hospital psiquiátrico e o CAPS, a partir delas, começam a representar no atual contexto do cuidado:

A construção dos $\boldsymbol{C A P S}$ veio realmente pra evitar que pessoas sejam simplesmente amontoadas num espaço e lá sejam esquecidas [...] os $\boldsymbol{C A P S}$ vieram com o intuito de tirar, de não animalizar o homem, e eu acho que é esse o ponto mais importante. (T1)

[...] era um tratamento muito desumano, você manter pessoas presas como animais, assim de maneira muito desumana, então essa nova proposta do tratamento em saúde mental ela veio realmente humanizar essa relação profissional-paciente, profissional-família, famíliapaciente. (T2)

$\mathrm{O}$ aparecimento de graves questionamentos com relação à ciência e à instituição psiquiátrica está estreitamente ligado a um dos maiores instrumentos utilizado pela terapêutica adotada nesse campo: a privação. Privação da liberdade, do contato familiar e social de uma maneira geral, das trocas estabelecidas na cotidianidade, privação da condição de ser humano.

Estudos anteriores realizados em Alagoas com o objetivo de conhecer a percepção de pessoas que têm em suas experiências a vivência tanto de internações em hospital psiquiátrico quanto de assistência recebida em CAPS, identificam os hospitais e a internação como sinônimo de prisão, violência, privação, perdas, sofrimento, entre outros; e a experiência do cuidado recebido nos CAPS como sinônimo de liberdade, resgate da cidadania e identidade, retorno à vida familiar e à casa, entre outros ${ }^{10,11}$.

As novas proposições de cuidado em saúde mental tiram do foco a doença e passam a focar o sujeito e, é por isso, que o estabelecimento de novos espaços para o exercício desse cuidado é tão necessário. Espaços onde trocas reais sejam incitadas e potencializadas, que possam reconhecer as necessidades e diferenças de cada sujeito, que estendam as suas ações à comunidade, ao território e à cidade nos seus mais diversos setores. 
A construção dos CAPS, nesse sentido, tem gerado processos antimanicomiais, pois o modo como são pautadas as suas intervenções os tornam dispositivos efetivos de tensão entre novas práticas e velhos hábitos ${ }^{12}$.

Para uma conduta diferente, entretanto, é preciso perceber que a crítica ao hospital psiquiátrico como lugar desumano e antiterapêutico não pertence apenas ao hospital ou ao manicômio, mas sim à ideologia psiquiátrica (da qual eles são produtos). Sem essa percepção, corremos o risco de reproduzirmos a mesma ideologia na criação de outros cenários $^{13}$.

\section{Tema 2: O CAPS como instância de ação do novo cuidado}

O crescimento numérico dos CAPS por todo o estado de Alagoas possibilitou uma nova experiência de cuidado a muitas pessoas que só conheciam a internação como forma de tratamento.

A valorização do cuidado nesses locais está presente na fala dos entrevistados:

Aqui tem mais liberdade... porque aqui eu estou todos os dias perto da minha filha... Eu tenho uma filha de cinco anos, ela mora com a minha irmã, mas toda noite ela vai lá pra minha casa [...] a minha filha vai pra lá e aqui eu tenho mais liberdade. (U2)

[...] o CAPS é uma assistência permanente, continuada, mas que tira da instituição. Quer dizer, você tem uma tendência a auxiliar os usuários a não se afastar da rotina familiar, da sua autonomia, da sua vida produtiva. (T3).

Essa recente modalidade de cuidado é marcada pela construção de uma nova postura ética em relação aos indivíduos acometidos por transtornos mentais. O sujeito não deve ser visto como portador de uma doença que precisa ser controlada, mas sim como pessoa que, devido às suas diferenças, necessita de locais e pessoas que o ajudem a garantir sua cidadania, a sua qualidade de vida, enfim, as suas trocas sociais e afetivas ${ }^{14}$.

A expansão desses novos serviços responde à necessidade de ofertar à sociedade espaço de atenção em saúde mental que se constitua para além das consultas, medicações e muros institucionais. $\mathrm{O}$ acolhimento das pessoas em sofrimento mental dentro desse novo espaço deve se constituir através do apoio de resgate de autonomia, respeito à cultura, particularidades e direitos, além de estímulo à integração familiar e social ${ }^{11}$.

A imagem do CAPS é percebida como uma imagem aberta à diversidade: diversidade de pessoas, de ações, de espaços, de afetos. A imagem da porta aberta, da família de braços abertos é apontada nas falas:

O CAPS pra mim é... uma família. Uma família que me acolheu nas minhas angústias, que eu estava sozinho em casa com aquela depressão tremenda e eu fui solicitado ao CAPS e hoje eu não estou mais com aquela depressão... (U2)

Aqui [no CAPS] todo mundo me trata bem, com cordialidade, aceita as minhas limitações, sabe dos meus potenciais. (U4)

[...] e essas meninas [profissionais do CAPS], elas têm um amor e têm um carinho por esse povo, que eu sempre observo, sempre eu venho aqui e eu observo e vejo... (F1)

O CAPS é de uma riqueza fantástica pela multiplicidade, porque você não soma em CAPS, você potencializa. (T4)

Consideramos que as transformações nos modelos de atenção em saúde mental devem ir para além da implantação e ampliação das redes de serviços, elas devem conduzir a outro saber que exige flexibilidade nas ações e mudanças individuais e coletivas de todos os envolvidos nesse processo.

É possível analisar que, para os trabalhadores, a percepção da necessidade de mudanças em suas ações valoriza o trabalho e é uma necessidade do serviço:

Não dá pra você ficar muito engomadinho... 'eu sou profissional, eu sou psicóloga, estou ali na minha salinha fechada [...]' Até porque a gente trabalha em conjunto. A enfermeira trabalha junto com a assistente social, a assistente social está junto com a psicóloga, participando dos grupos, dependendo do momento, dependendo da abordagem. (T1)

Existe uma importância da contribuição dos diversos profissionais nas diversas ações: todas as ações de você incluir o doente mental na sociedade, com as diversas formas de contar com as diversas instituições, você favorecer a inclusão social, a possibilidade de você quebrar toda essa contenção, de passar para a sociedade que ela tem que se transformar para entender o portador de transtorno mental (T6).

Os CAPS, portanto, devem se aproveitar de sua potencialidade de um fazer coletivo solidário e experimental, tornando-o um campo instigante de cooperação, reflexão, autoanálise e ressignificação de práticas ${ }^{12}$.

Para tanto, as relações constituídas a partir dessa nova proposta de cuidado devem levar em consideração 
todos os atores envolvidos nesse coletivo: o usuário, sua família, a comunidade no entorno, os trabalhadores e cuidadores, as instituições que fazem parte da rede de cuidado e aquelas que fazem parte da rede de vida da comunidade, a Universidade que forma profissionais para o exercício do cuidado, os gestores que criam processos políticos, organizacionais e de trabalho comprometidos com este cuidado e uma infinidade de outros personagens que podem ingressar no plano coletivo de forças para potencializar as produções de subjetividades.

\section{Tema 3: O CAPS e seus usuários: da dor à liberdade}

Ao se referirem às suas histórias e situações vividas, algumas falas são carregadas de imagens ligadas à doença e seu sofrimento:

[...] eu era uma pessoa que tinha muita depressão com qualquer coisa, com a caneta, como eu passei a dizer a você, com as cores, cores verde, cores amarela ou preta, aquelas cores me indicavam um sentido... o preto significava o pecado, o vermelho significa o sangue derramado na face da terra, o verde significava a esperança [...] (U2)

[...] só que ela vivia numa situação, que, ela tirava a roupa, ficava pelada, andava por todo canto, uma situação triste, pesada... [...] Ela ficava agitada, ficava agressiva, ficava nervosa... (F1)

A vivência de ser diferente, de sentir ou perceber o mundo de forma diferenciada e manifestar-se contrariamente ao que a maioria espera, marca o início do sofrimento psíquico.

Preconceito, discriminação, segregação, estigma, exclusão, são palavras bastante usadas nos relatos:

[...] porque as famílias que têm um parente com necessidades especiais o tratam como se fossem uma cruz pra carregar, um martírio. Você joga em casa, não deixa sair... (U4)

É muito difícil você trabalhar com saúde mental, existe ainda muito preconceito, o estigma do louco também é muito difícil você trabalhar, tanto é que quando a gente passa, o povo pergunta: 'trabalha aonde? No CAPS? Ah... lá no lugar dos doidos...' Então assim, existe muito preconceito... (T2)

[...] às vezes nos grupos eles [os usuários] falam muito isso 'olhe eu vinha no ônibus, no ônibus escolar e quando descobriram que eu era do CAPS começaram a dizer: olhe o doido, é o doido' então já começa a ser colocado de escanteio $[\ldots]$ (T3)

Essas falas corroboram a ideia de que há dor e sofrimento não apenas na manifestação sintomatológica do transtorno mental, e estes sentimentos são detectados não na relação do sujeito com ele mesmo, mas na relação dele com os outros.

A experiência do sofrimento desses sujeitos é também a experiência do seu silenciamento e sua exclusão social. Apesar das portas do manicômio terem sido abertas, as portas da sociedade e de sua cultura de exclusão do diferente ainda não foram.

$\operatorname{Basaglia}^{2}$ (p.134), ao analisar a natureza do preconceito afirma não se tratar de uma postura psicológica individual, mas sim da "expressão dos valores da sociedade em que o indivíduo está inserido, resultado de uma seleção discriminante entre normalidade e anormalidade, bem e mal, maioria e minoria, poder e não-poder".

Fonseca et al. ${ }^{15}$ apontam que apesar do manicômio como edificação e espaço epistêmico encontrar-se, na atualidade, em estado de ruína, sua visão e ação sobre a diferença ainda permanecem impregnadas nas mentes dos sujeitos e dobradas em seus corpos.

Por isso, a desinstitucionalização deve ser entendida como um processo contínuo e seu alcance não deve estar limitado às esferas da saúde e do cuidado, mas sim, deve ser espalhado em todos os espaços do cotidiano, alastrado em todas as dimensões que expressam a vida em sociedade.

As ações de cuidado não devem estar limitadas apenas às estruturas institucionais, pois estas não dão conta de transformar as relações manicomiais que a sociedade estabelece com a loucura. Como indica Bezerra ${ }^{16}$ (p.113) "a desconstrução do manicômio implica necessariamente reinventar não só a psiquiatria, mas - no limite - a própria sociedade em que vivemos".

Resgatar este sujeito da vivência exclusiva da doença e dos encargos que esta traz é trazê-lo a uma nova constituição de vida que não se faz no entorno apenas do indivíduo, mas se faz no entorno da sociedade e da cultura que a rege.

No contexto do CAPS o cuidado deve ser organizado para ir muito além de amenizar/tratar o sofrimento causado pela doença ou garantir direitos dos seus usuários, ele deve visar à criação de espaços de tolerância, modos de acolhimento, convivência e solidariedade.

Nesse sentido, nossos entrevistados apontam a importância do estabelecimento de novas relações no cuidado, baseadas também no afeto: 
[...] a gente se apega, às vezes brincando, não machucando, com amizade, como aquela senhora, da diretoria, aquela baixinha, eu pego, chamo ela de madame [risos] e ela dá risada, tudo bem... Na realidade, eles tratam como se fosse... é claro que não pode ser... mas eles nos tratam nós como se fosse tudo por igual, entende? Isso eu sinto... (U1)

E aqui eu tenho liberdade também de conversar com os meus colegas, com as auxiliares, com o, como é que se diz, o farmacêutico, que me atende muito bem é uma pessoa sorridente, que é o , me respeita, tudo bem...

Aqui eu tenho mais liberdade. (U2)

Essas falas parecem evidenciar que o fato do CAPS propiciar relações mais horizontais, mais democráticas e mais afetivas faz com que os seus usuários passem a experimentar sentimentos de inclusão, de pertencimento e, por conseguinte, de satisfação e liberdade.

A experiência cotidiana de construção de vínculos acontece dentro da estrutura dos serviços, mas deve ser sustentada e estimulada pelos trabalhadores através do estímulo de encontros que vão sendo tecidos por alteridade e produzem afetos.

Outro aspecto importante apontado é que os CAPS, por serem serviços abertos, possibilitam o desenvolver de potencialidades, o despertar de novos desejos e a inserção em novos contextos:

Desenvolvimento de potenciais, de habilidades, reconhecimento de limitações... A pessoa te tratar com isonomia, sabe? Igualdade... Como tem que ser. Não é porque você é diferente... (U4)

[...] fazer ele [o usuário] ir mais adiante, vendo as possibilidades de reintrodução desse portador no mercado de trabalho, na profissionalização. (T5)

O novo cuidado em saúde mental trabalha em cima da singularidade e potencialidade dos sujeitos assistidos. Cria dispositivos e situações que facilitem a (re)descoberta de sujeitos que estavam ocultos.

Assim, estes novos sujeitos são chamados a reescreverem a sua história, ressignificando o seu papel social, encontrando caminhos de identificação, estabelecendo novas relações com a vida e, principalmente, com eles mesmos:

Eu vendo caneta, chaveiro, agenda telefônica, papel de presente, caixa de presente e aí vai... Aí eu trago aqui. $\mathrm{O}$ pessoal gosta muito. $\mathrm{O}$ meu trabalho é um trabalho bonito, todo mundo gosta e eu gosto de sorriso... Amo esse trabalho, eu amo esse trabalho mesmo, eu amo ele e eu pra conseguir esse trabalho todinho, do começo até o fim, eu lutei 30 anos... E ninguém toma. Só quem tem sou eu e eu tenho o meu e-mail que é ___ e aí vai pra lá e o meu nome está divulgado por todo canto... (U5)

Nosso sujeito, em sua fala, imprime o sentido da desinstitucionalização: formulação de desejos, expressão de inserção, de participação, de reconhecimento e de protagonismo de sua própria história.

Somente com o trabalho de construção de um lugar social real para esses sujeitos é que eles poderão dar liberdade aos seus desejos e realizar seus sonhos:

Eu quero sempre minha evolução, meu progresso, melhoria... Quero ter vida social, vida afetiva, quero vida profissional.... (U4)

Para a conquista desses desejos, o cuidado em saúde mental deve estar alicerçado em um novo conceito de subjetividade, em que a contínua reconstrução de identidades seja estimulada e que a ideia de produção, relacionada à dimensão transformadora, seja abraçada pela noção de sucesso prático, podendo ou não passar pela produção de bens ${ }^{17}$ (Ayres, 2001).

Longo caminho a ser trilhado... caminho que envolve mudanças de conceito e prática entre os profissionais de saúde, mudanças sociais, políticas, econômicas, que somadas, irão refletir no cotidiano da sociedade ${ }^{10}$.

Assim, é preciso criar dispositivos, oportunidades e situações que auxiliem a descoberta de valores e potências silenciadas pela opressão da diferença. Esta constatação nos faz refletir sobre a necessidade de trazer para essa trama, novos fios, que componham desenhos criativos traçados em tantas mãos quanto forem possíveis se fazerem presentes.

\section{CONSIDERAÇÕES FINAIS}

A reforma do pensamento e a construção de um novo saber são caminhos de transformações paradigmáticas que reforçam a necessidade de aproximação da ciência com a sociedade. Para Morin ${ }^{18}$, o conhecimento passa a ser amparado por um paradigma complexo, reforçando a ideia da necessidade em entender o ser humano não mais como objeto, mas como sujeito.

É esse sujeito que a desinstitucionalização luta para libertar. Sujeito de direito, sujeito de desejos, sujeito de história, de relações, de trocas, de produções, sujeito de vida. Se, durante anos, a ciência, investida pelo mandato 
que a sociedade lhe atribuiu, afastou este sujeito do convívio social, por não conseguir compreender as suas diferenças, é esta ciência também que deve ter o compromisso de resgatá-lo.

Assim, com o novo paradigma introduzido pela noção da desinstitucionalização e do movimento da Reforma Psiquiátrica no campo do cuidado em saúde mental, muitas questões se apresentam para a melhor definição das prioridades nesse novo cenário - não mais no enclausuramento institucional, mas no cuidado exercido no território, entendido como conjunto de processos de convivência expresso pela vida local.

A presente pesquisa traz no seu âmago a ideia de que a construção de um novo cuidado em saúde mental faz parte dessa transformação paradigmática que a pósmodernidade impulsiona, sujeitos na coletividade em constantes processos de renovação.

As relações constituídas a partir dessas mudanças não mais se limitam às relações do tratamento biomédico ou, no presente caso, das tão limitadas ações psiquiátricas, mas são relações constituídas no compromisso social do coletivo, em que a saúde mental passa a ser um campo de conhecimento interdisciplinar e suas ações passam a se dar por meio de uma dinâmica de trabalho em rede.

Esse processo implica uma mobilização de todos os atores envolvidos no cuidado, em ações terapêuticas voltadas para a produção de vida, de sentido, de sociabilidade e transformação dos espaços de não convivência em espaços coletivos.

Assim, a desinstitucionalização em saúde mental atualiza-se como processo contínuo de transformação na compreensão do sofrimento psíquico, no entendimento das necessidades do sujeito e na valorização de seu protagonismo.

Dentro desse propósito, oferece-se um novo lugar social para as pessoas acometidas pelo sofrimento psíquico, um lugar de significação e subjetivação na compreensão da vivência do sofrer psíquico, mas, também, na compreensão do viver com novas perspectivas, com novos desejos.

AGRADECIMENTO: À Fundação de Amparo à Pesquisa de Alagoas (FAPEAL) que viabilizou a realização deste empreendimento científico.

\section{REFERENCIAS}

1. Goffman E. Manicômios, prisões e conventos. 7a ed. São Paulo: Perspectiva; 2003.

2. Basaglia F. Escritos selecionados em saúde mental e reforma psiquiátrica. Rio de Janeiro: Garamond; 2005.

3. Rotelli F, Leonardis O, Mauri D. Desinstitucionalização, uma outra via: a reforma psiquiátrica Italiana no contexto da Europa ocidental e dos países avançados. In: Nicácio F, organizador. Desinstitucionalização. 2a ed. São Paulo: Hucitec; 2001.

4. Amarante P. Uma aventura no manicômio: a trajetória de Franco Basaglia. Hist Cienc Saude - Manguinhos, Rio de Janeiro. 1994;1(1):61-77. http://dx.doi.org/10.1590/S010459701994000100006

5. Rotelli F. O Inventário das subtrações. In: Nicácio F, organizador. Desinstitucionalização. São Paulo: Hucitec; 2001. p.61-4.

6. Amarante P. Loucos pela vida: a trajetória da reforma psiquiátrica no Brasil. Rio de Janeiro: Fiocruz; 1995.

7. Brasil. Ministério da Saúde. SAS/DAPES. Coordenação Geral de Saúde Mental, Álcool e Outras Drogas. Saúde mental em dados 10. Informativo eletrônico, Brasília. 2012 mar.;8(10) [citado em 1 mar. 2013]. Disponível em: http://portal.saude. gov.br/portal/arquivos/pdf/mentaldados10.pdf .

8. Bardin L. Análise de conteúdo. São Paulo: Edições 70; 2011.

9. Minayo MCS. O desafio do conhecimento: pesquisa qualitativa em saúde. 12a ed. São Paulo: Hucitec; 2010.

10. Pereira MA, et al. A assistência psiquiátrica sob o ponto de vista do doente mental: antes e depois da reforma psiquiátrica. In: Labate RC, organizador. Caminhando para a assistência integral. Ribeirão Preto: Scala; 1999.

11. Brêda $M Z$, Ribeiro MC, Silva PPAC, Silva RCO, Costa $T F$. $A$ avaliação dos centros de atenção psicossocial do estado de Alagoas: a opinião dos usuários. Rev Rene - Rev Rede Enferm Nordeste. 2011;12(4):818-24 [citado 10 nov. 2013]. 
Disponível em: http://www.revistarene.ufc.br/revista/index. php/revista/article/view/302.

12. Merhy EE. Os CAPS e seus trabalhadores no olho do furacão antimanicomial. Alegria e alívio como dispositivos analisadores. In: Amaral H, Merhy EE, organizadores. A reforma psiquiátrica no cotidiano II. São Paulo: Aderaldo \& Rothschild; 2007. p.55-66.

13. Saraceno B. Libertando identidades: da reabilitação psicossocial à cidadania possível. Belo Horizonte: Te Corál Instituto Franco Basaglia; 1999.

14. Ribeiro MC, Machado AL. A terapia ocupacional e as novas formas do cuidar em saúde mental. Rev Ter Ocup Univ São Paulo. 2008;19(2):72-5. doi: http://dx.doi.org/10.11606/ issn.2238-6149.v19i2p 72-75

15. Fonseca TMG, Engelman S, Perrone CM. Rizomas da reforma psiquiátrica: a difícil reconciliação. Porto Alegre: Sulina/ UFRGS; 2007. p.29-52.

16. Bezerra Junior B. Cidadania e loucura: um paradoxo? In: Bezerra Junior B, Amarante P, organizadores. Psiquiatria sem hospício: contribuições ao estudo da reforma psiquiátrica. Rio de Janeiro: Relume-Damará; 1992.

17. Ayres JRCM. Sujeito, intersubjetividade e práticas de saúde. Cienc Saude Coletiva. 2001;6(1):63-72. http://dx.doi. org/10.1590/S1413- 1232001000100005

18. Morin E. Educação e complexidade: os 7 saberes e outros ensaios. 4a ed. São Paulo: Cortez; 2007.

Recebido para publicação: 19/09/2013

Aceito para publicação: 23/11/2013 